\title{
An Experimental Investigation of Thermal Properties of Fabric Reinforced Epoxy Composites
}

\author{
IULIAN GABRIEL BIRSAN, VASILE BRIA, MARINA BUNEA*, ADRIAN CIRCIUMARU \\ Research and Development Center for Thermoset Matrix Composites, Dunarea de Jos University of Galati, 111 Domneasca \\ Str., 800008, Galati, Romania
}

\begin{abstract}
Specific heat and thermal linear expansion coefficient of epoxy composites reinforced with carbon, aramid, glass and hybrid fabrics with unfilled and filled stratified matrices were studied. The thermal measurements of specific heat were performed with Differential Scanning Calorimeter (DSC instrument) and those of thermal coefficient of linear expansion were realized with Thermomechanical Analyzer (TMA instrument). It was analyzed the influence of fiber orientation at various angles $\left( \pm 15^{\circ}\right.$, $\pm 30^{\circ}$ and $\pm 45^{\circ}$ ) and the effects of two types of filler mixtures added into polymeric matrix on the thermal behavior of composite materials. It was found that in case of epoxy matrix the added filler mixtures reduced its thermal coefficient of linear expansion and had an insignificant influence on specific heat. In case of epoxy composites reinforced with fabrics, the fiber orientation and fillers addition showed different effects on the investigated thermal parameters in dependence of the used reinforcement types.
\end{abstract}

Keywords: Epoxy composite; Fabric reinforcement; Thermal expansion coefficient; Specific heat

\section{Introduction}

The composite materials with thermosetting matrix and reinforced with different types of fibers or fabrics are used in all domains due to their high mechanical properties (high strength and stiffness), lightweight and low cost. Most often are used the epoxy composite materials. In order to select a composite material for a specific application, besides mechanical properties there are taken into account the thermal properties as thermal conductivity, specific heat and linear expansion coefficient, if the intended application involves the use of material during service time at high or low temperature or at temperature value variations. The mechanical resistance of the materials depends on thermal deformation [1-3], because the ductility of a material increases with the temperature increasing and its fragility increases with the temperature decreasing. In order to analyze the thermomechanical behavior of a material, it is investigated its linear expansion coefficient due to changing of the volume and dimensions with the temperature variation, which can affect the structural stability.

The thermal behavior of the fabric reinforced epoxy composites depends on the properties, amount and configuration of the each constituent material and the quality and properties of the fiber-matrix interphase. Also, their thermal properties of the composites reinforced with fibers depend on fiber orientation, fabric weave type, specific density and thickness. It was found that the carbon pre-preg with eight-harness satin weave showed higher specific heat by an amount of $4 \%$ as compared to the ones with plain weave and unidirectional tape [4]. As reinforcement for epoxy composites most often are used the plain fabrics due to their high structural stability [5], the same mechanical resistance in both fiber directions [6] and delamination strength [7], but regarding the thermal behavior it was found that the thermal conductivities of the composites reinforced with plain weave fabrics exhibit values between those of unidirectional lamina with fiber orientation at angles as $0^{\circ}$ and $90^{\circ}$ [8]. The unidirectional lamina at $0^{\circ}$ presents a higher thermal conductivity than those at $90^{\circ}$. The thermal properties depends on the properties of the fiber type, so as at temperatures greater than $0^{\circ} \mathrm{C}$, the composites reinforced with carbon fibers showed a higher heat capacity as compared to the ones reinforced with glass fibers and vice versa at negative temperatures [9].

\footnotetext{
*email: marina.bunea@ugal.ro
} 
In order to enhance the thermal, electrical and mechanical properties of the fabric reinforced epoxy composites, hybrid epoxy materials can be designed and formed by using different types of fabrics and/or by addition of different types of fillers into polymeric matrix. In several areas, such as car, aircraft and maritime constructions the glass fibers and glass fiber fabrics are used most often due to their high chemical and corrosion resistance and low cost. In order to enhance the in-plane thermal conductivity, their outer layer can be replaced by carbon fiber or fabric plies [10], but if it is pursued the improvement of their thermal properties through thickness of the composite material, it can be performed by adding of fillers into polymeric matrix [11]. The hybrid composites combine the advantages of all used constituent material and reduce their disadvantages, but it has to be taken into account filler properties, particles shape and size [12], their compatibility, orientation, uniform distribution and the quality of filler-matrix interphase [13,14], because in dependence of the used fillers the mechanical resistance of the composite material can be affected by improving its thermal and electrical properties. The properties and quality of filler-matrix interphase can be improved by reduction of particles size, which lead to an increasing of interfacial interaction between the filler and polymer [15]. Regarding the thermomechanical behavior of the epoxy composites there can be formed thermostable composites, which do not modify their dimensions in heating or cooling conditions by combining the constituent materials with low and high thermal linear expansion coefficients [16], but in the case of filler usage they should not exceed the amount of $30-40 \%$ to avoid their arrangement in different directions and formation of multiple geometric patterns [17]. It was found that the addition of single- and multi-walled carbon nanotubes [18,19], graphene platelets [18,20], graphene oxide [18], boron nitride sheets [20], carbon black [19,21,22], nano-ferrites [23], etc. into epoxy composites improved their thermal conductivity.

For this study there were formed three classes of epoxy composites reinforced with carbon, aramid and glass fabrics with: fiber orientation at $0^{\circ}\left(1^{\text {st }}\right.$ class), fiber orientation at various angles $\left(2^{\text {nd }}\right.$ class), fiber orientation at various angles and stratified filled matrix ( $3^{\text {rd }}$ class). The fabric reinforced epoxy composites with fiber orientation at various angles and stratified filled matrix were formed in order to obtain the multifunctional advanced materials with improved thermal, electrical and mechanical properties. In this paper it is presented the investigation of thermal parameters as specific heat and thermal linear expansion coefficient of these composite materials. The influence of fiber orientation at various angles and filler addition into polymeric matrix on these thermal properties had been analyzed.

\section{Materials and methods}

For epoxy matrix of composite materials reinforced with fabric, it was used EPIPHEN 4020 epoxy bi-component system (Bostik, Germany) made of RE resin and DE hardener ratio of 100:30. This epoxy system was selected due to its physical properties before polymerization, which are important to form composite materials, and thermal, electrical and mechanical properties after complete polymerization. Its complete polymerization is achieved after 14 days at laboratory conditions with temperature of $23^{\circ} \mathrm{C}$ and humidity of $50 \%$.

As reinforcement of epoxy composite materials there were used four types of plain woven fabrics: carbon fiber fabric with specific density of $160 \mathrm{~g} / \mathrm{m}^{2}$ and thickness of $260 \mu \mathrm{m}$, denoted as $C$; aramid fiber fabric with specific density of $173 \mathrm{~g} / \mathrm{m}^{2}$ and thickness of $280 \mu \mathrm{m}$, denoted as $A$; glass fiber fabric with specific density of $163 \mathrm{~g} / \mathrm{m}^{2}$ and thickness of $180 \mu \mathrm{m}$, denoted as $G$; hybrid fiber fabric with three alternating different yarns and copper wire in the weft direction with specific density of $270 \mathrm{~g} / \mathrm{m}^{2}$ and thickness of $330 \mu \mathrm{m}$, denoted as $H$.

The hybrid fiber fabric is a modified mixed carbon/aramid fibers fabric with specific density of $165 \mathrm{~g} / \mathrm{m}^{2}$ and thickness of $230 \mu \mathrm{m}$. The woven geometry of this mixed carbon/aramid fibers fabric represents 2 carbon fiber yarns: 1 aramid fiber yarn in the warp direction and 1 carbon fiber yarn: 2 aramid fiber yarns in the weft direction. The modification of mixed fabric was performed by replacing of each second aramid fiber in the weft direction with a glass fiber with linear density of 200tex and a 
tinned copper wire with the diameter of $0.2 \mathrm{~mm}[24,25]$. This hybrid fabric was realized for the medial layer of studied composite materials.

Because all properties of the fabric reinforced epoxy composites depends on the quality and properties of fiber-matrix interphase due to their adherence, all fabrics were treated by uniform spraying with detergent, sodium hydroxide and perchloric acid solutions and cleaned with water after each treatment. Then the treated fabrics were dried and covered by an uniform spraying with a thin epoxy film made of selected bi-component system mixed with nitro diluent to improve. This treatment ensured also the fabrics stability during the lamina cutting and composite forming processes.

There were formed three classes $\mathrm{C} 0, \mathrm{C} 1$ and $\mathrm{C} 2$ of fabric reinforced epoxy composites with 17 reinforcement layers, each medial ply is made of hybrid fabric. Three epoxy composites had been formed for each class of materials. These materials are reinforced with the same type of fabric excepting the medial layer, as follows: $\mathrm{CE}$ - carbon fabric reinforced epoxy composite, $\mathrm{AE}$ - aramid fabric reinforced epoxy composite and GE - glass fabric reinforced epoxy composite. The difference between the material classes consists in fiber orientation and epoxy matrix type. So, the composite materials of class $\mathrm{C} 0$, named here CE0, AE0 and GE0, have the fiber orientation at $0^{\circ}$, except for the medial ply, whose fiber orientation for all investigated materials is at angle $0 \mathrm{f} 90^{\circ}$, and unfilled epoxy matrix. The stratified epoxy composite materials of classes $\mathrm{C} 1$ and $\mathrm{C} 2$ have the fiber orientation at various angles: CE1 and CE2 $\left[0^{\circ} / 45^{\circ} / 0^{\circ} / 30^{\circ} / 15^{\circ} /-30^{\circ} / 0^{\circ} / 30^{\circ} / \mathrm{H} 90^{\circ} /-30^{\circ} / 0^{\circ} / 30^{\circ} /-15^{\circ} \%-30^{\circ} / 0^{\circ} / 45^{\circ} / 0^{\circ}\right]$, AE 1 and AE $2\left[0^{\circ} / 45^{\circ} / 30^{\circ}\right.$ $\left./ 15^{\circ} /-30^{\circ} /-15^{\circ} / 30^{\circ} / 45^{\circ} / \mathrm{H} 90^{\circ} / 45^{\circ} /-30^{\circ} / 15^{\circ} / 30^{\circ} \%-15^{\circ} /-30^{\circ} / 45^{\circ} / 0^{\circ}\right]$ and GE1 and GE2 [45\% $/ 30^{\circ} / 15^{\circ} /-$ $\left.30^{\circ} / 45^{\circ} / 30^{\circ} /-15^{\circ} / 45^{\circ} / \mathrm{H} 90^{\circ} / 45^{\circ} / 15^{\circ} /-30^{\circ} / 45^{\circ} / 30^{\circ} /-15^{\circ} /-30^{\circ} / 45^{\circ}\right]$. The epoxy matrix type represents the difference between the materials of classes $\mathrm{C} 1$ and $\mathrm{C} 2$. So, for composite materials of class $\mathrm{C} 1$ it was used an unfilled epoxy matrix, but for the ones of class $\mathrm{C} 2$ there were used two filled epoxy resins. The filled epoxy matrix had been modified by adding of two types of filler mixtures, such as: MM1 - prepolymer mixture with $10 \mathrm{wt}$. \% of aramid powder, $10 \mathrm{wt}$. \% of carbon black and $10 \mathrm{wt} . \%$ of potatoes starch used for layers 01 to 05 and 13 to17; MM2 - pre-polymer mixture with $10 \mathrm{wt} \%$ of potatoes starch, $10 \mathrm{wt}$. \% of barium ferrite and $10 \mathrm{wt}$. \% of carbon black used for layers 06 to 12 leading, this way, to a stratified matrix.

In order to form the fabric reinforced epoxy laminates it was used wet lay-up method. After complete polymerization has been achieved, the epoxy composite plates were thermally cured and the specimens for thermal measurements were extracted by using a water jet cutting machine.

In order to perform the thermal measurements the instruments from Mettler Toledo and software STARe for acquisition and evaluation of data were used. The thermal linear expansion coefficient was measured with thermomechanical analyzer TMA SDTA 840 instrument for the temperature range from $30^{\circ} \mathrm{C}$ to $200^{\circ} \mathrm{C}$ with a heating ratio of $20^{\circ} \mathrm{C} / \mathrm{min}$. The rectangular specimens with the surface dimensions $10 \times 5 \mathrm{~mm}$ were used and the measurements were performed on the reinforcement plane. In Figure 1 it is plotted the typical thickness vs temperature curve of TMA measurements for a specimen of a fabric reinforced epoxy composite in the temperature range from $30^{\circ} \mathrm{C}$ to $200^{\circ} \mathrm{C}$.

The thermal measurements of specific heat were performed using Differential Scanning Calorimeter (DSC 1 instrument) for the temperature range from $30^{\circ} \mathrm{C}$ to $330^{\circ} \mathrm{C}$ and cooling temperature range from $330^{\circ} \mathrm{C}$ to $30^{\circ} \mathrm{C}$ with a heating/cooling ratio of $20^{\circ} \mathrm{C} / \mathrm{min}$. For specific heat measurements cylindrical specimens with diameter of $3 \mathrm{~mm}$ were used. The thermal investigation was performed, also, for unfilled matrix ME and for filled matrices MM1 and MM2 to analyze the effects of filled mixtures on thermal properties. For example, in Figure 2 are presented the typical heat flow vs temperature (above) and specific heat vs temperature (below) of a specimen in DSC measurement of unfilled epoxy matrix in the mentioned temperature range.

\section{Results and discussions}

The analysis of thermal coefficient of linear expansion and specific heat was realized on the linear portion limits of the thickness vs temperature curves of TMA measurements and specific heat vs temperature curves of DSC measurements, which are plotted in Figures 1 and 2 . The thermal 
experimental investigation of thermal coefficient of linear expansion and specific heat of epoxy matrix types and fabric reinforced epoxy composite materials was performed in the temperature ranges of 4060 and $110-170^{\circ} \mathrm{C}$.

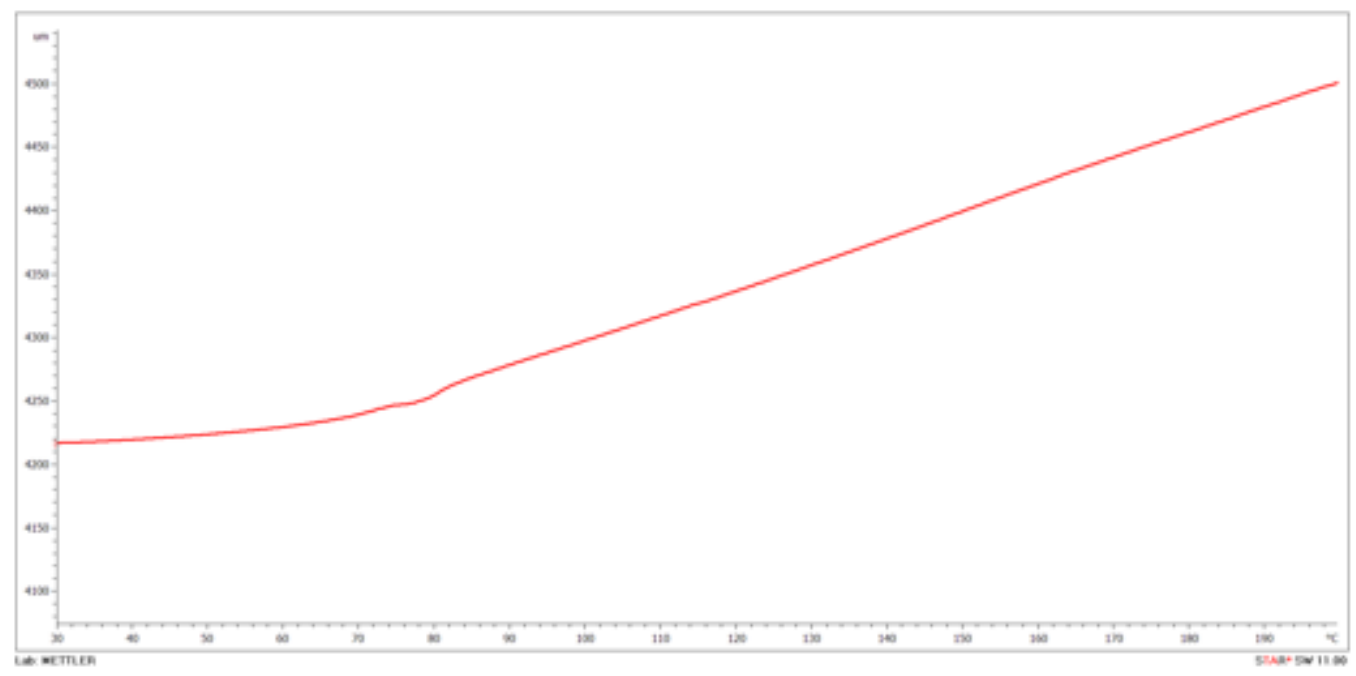

Figure 1. A typical thickness vs temperature curve of TMA measurements of a specimen

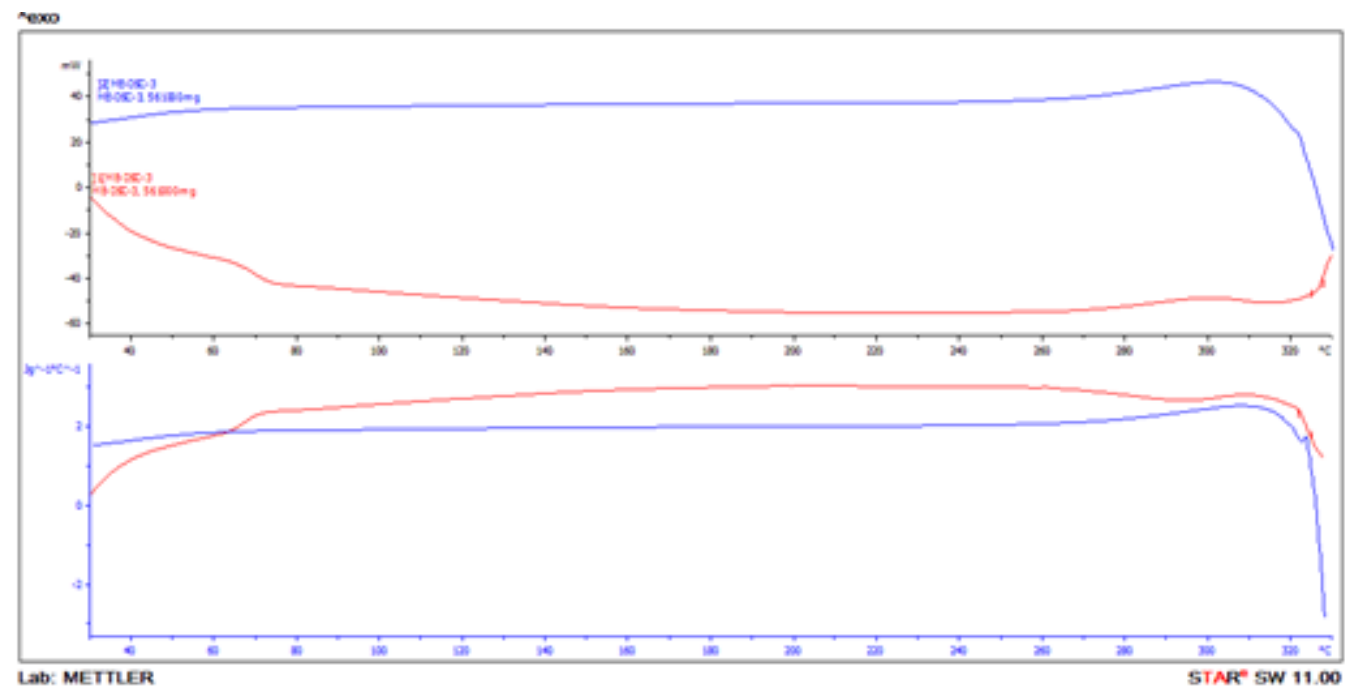

Figure 2. The typical heat flow vs temperature (above) and specific heat vs temperature (below) of a specimen in DSC measurements

The averaged values of thermal expansion coefficient of epoxy matrix types determined in the temperature ranges of $40-60$ and $110-170^{\circ} \mathrm{C}$ are presented in Figure 3 . It can be observed that the addition of filler mixtures led to a decreasing of values exhibited by thermal linear expansion coefficient for both temperature ranges. The obtained results showed that the addition of filler mixtures in epoxy matrix improved its thermomechanical behavior. The highest values of the coefficient of thermal linear expansion were obtained in case of unfilled epoxy matrix for both temperature ranges. 


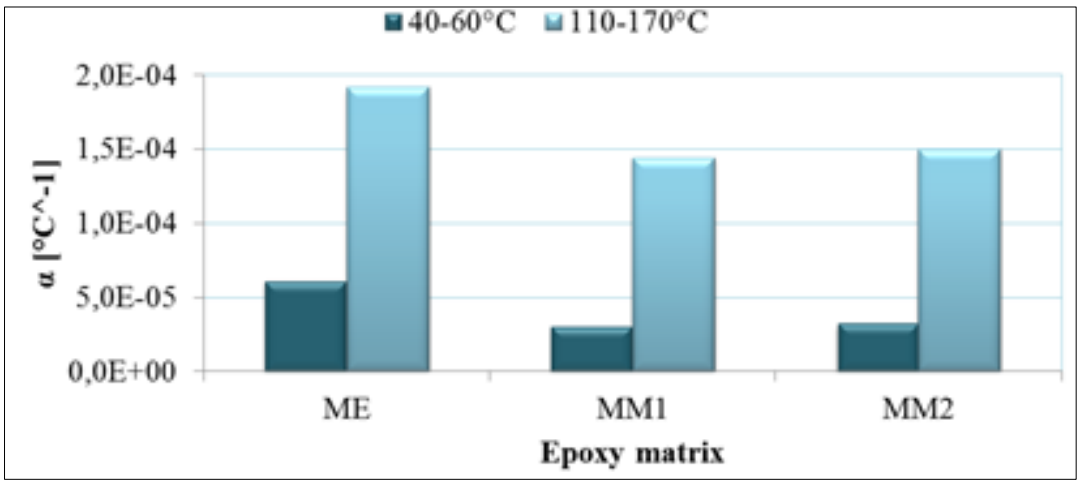

Figure 3. Coefficient of thermal linear expansion of epoxy matrix types

Due to experimental results obtained in ref. [26], which showed that corn starch in amount of $10 \%$ had no effects on thermal properties, but it was used to ensure the uniform distribution of fillers into polymer matrix, it will be taken in consideration the effects of the other used fillers.

So, in case of filled epoxy matrix MM1, the aramid powder and carbon black led to a decreasing of values presented by thermal expansion coefficient in the temperature range of $40-60^{\circ} \mathrm{C}$ by almost $50 \%$, but in the second temperature range of $110-170^{\circ} \mathrm{C}$ these values were reduced by almost $25 \%$. In case of filled epoxy matrix MM2, it was obtained that the barium ferrite and carbon black reduced the values of thermal expansion coefficient in the temperature range of $40-60^{\circ} \mathrm{C}$ by almost $46 \%$, but in the second temperature range of $110-170^{\circ} \mathrm{C}$ these values were reduced by almost $22 \%$.

In Figure 4 are plotted the averaged values of thermal expansion coefficient of fabric reinforced epoxy composites. It can be seen that in case of class $\mathrm{C} 0$ materials, the lowest values of thermal expansion coefficient in the first temperature range of $40-60^{\circ} \mathrm{C}$ were obtained for carbon fabric reinforced epoxy composite and the highest values were recorded for composite material reinforced with glass fabric. If we compare the values of thermal expansion coefficient of the same composite materials in the second temperature range of $110-170^{\circ} \mathrm{C}$, it can be seen that the best thermomechanical behavior was presented by the composite reinforced with aramid fabric. If we compare the expansion coefficient values of the classes $\mathrm{C} 0$ and $\mathrm{C} 1$ materials in the temperature range of $40-60^{\circ} \mathrm{C}$, it can be remarked that the fiber orientation at various angles improved the thermomechanical behavior of all fabric reinforced epoxy composites. So, the best TMA result was obtained in the case of composite reinforced with carbon fabric, whose expansion coefficient value was reduced by almost 33\%. In the temperature range of 110 $170^{\circ} \mathrm{C}$ the fiber orientation at various angles led to the increasing of the thermal coefficient values for all composite materials. If we compare the values of thermal linear expansion coefficient of the classes $\mathrm{C} 1$ and $\mathrm{C} 2$ materials on both temperature ranges, it can be seen that addition of filler mixtures into epoxy matrix led to the improvement of thermomechanical behavior of composite materials reinforced with carbon and glass fabric, but it increased the thermal coefficient values of aramid reinforced epoxy composite.

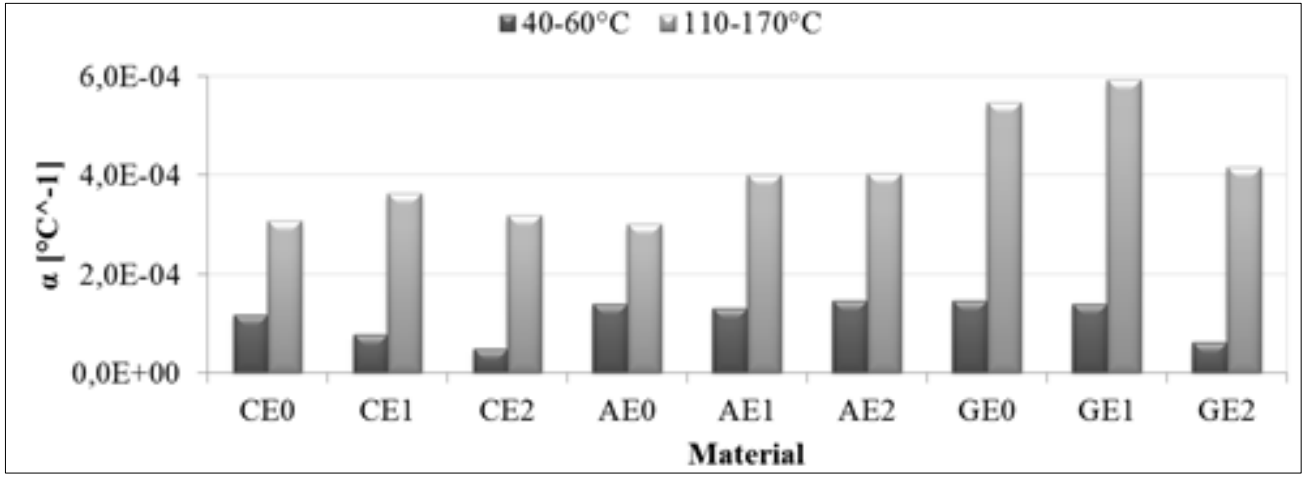

Figure 4. Thermal coefficient of linear expansion of all fabric reinforced epoxy composites 
Regarding the effects of fiber orientation at various angles and filler mixtures addition into epoxy matrix, it can be observed that the linear expansion coefficient showed reduced value by almost $58 \%$ for composites reinforced with carbon and glass fabrics in the temperature range of $40-60^{\circ} \mathrm{C}$, the values exhibited by aramid reinforced epoxy composite increased by almost $5 \%$. In the temperature range of $110-170^{\circ} \mathrm{C}$ the effects of fiber orientation at various angles and filler mixtures addition into epoxy matrix led to a decreasing by almost $24 \%$ of thermal coefficient value, recorded only in case of glass reinforced epoxy composite, but in case of composites reinforced with carbon and aramid fabrics the values of thermal linear expansion coefficient increased by almost $4 \%$ and $25 \%$, respectively.

In Figure 5 are plotted the values of specific heat of epoxy matrix types measured on both, heating and cooling test segments in the temperatures ranges of $40-60^{\circ} \mathrm{C}$ and $110-170^{\circ} \mathrm{C}$. It can be observed that the filler mixtures addition into epoxy matrix decreased insignificantly its specific heat values. Regarding the specific heat of fabric reinforced epoxy composites, their values measured in the heating temperature ranges of $40-60^{\circ} \mathrm{C}$ and $110-170^{\circ} \mathrm{C}$ are showed in Figure 6 . It can be observed that in the both temperature ranges the highest values of specific heat was obtained in case of composites reinforced with aramid fabric. If we compare the composite materials with fiber orientation at $0^{\circ}$ (class $\mathrm{C} 0$ materials), it can be remarked that the ones reinforced with carbon fabric showed higher values of specific heat as compared with the ones reinforced with glass fabric on both temperature domains.

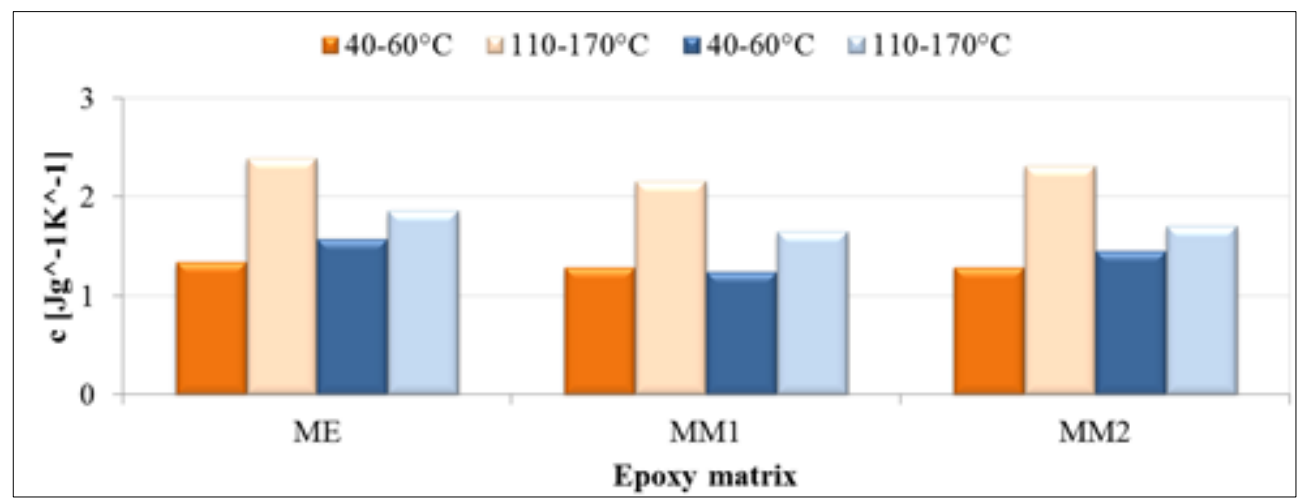

Figure 5. Specific heat of epoxy matrix types measured during both heating and cooling on the targeted temperature domains

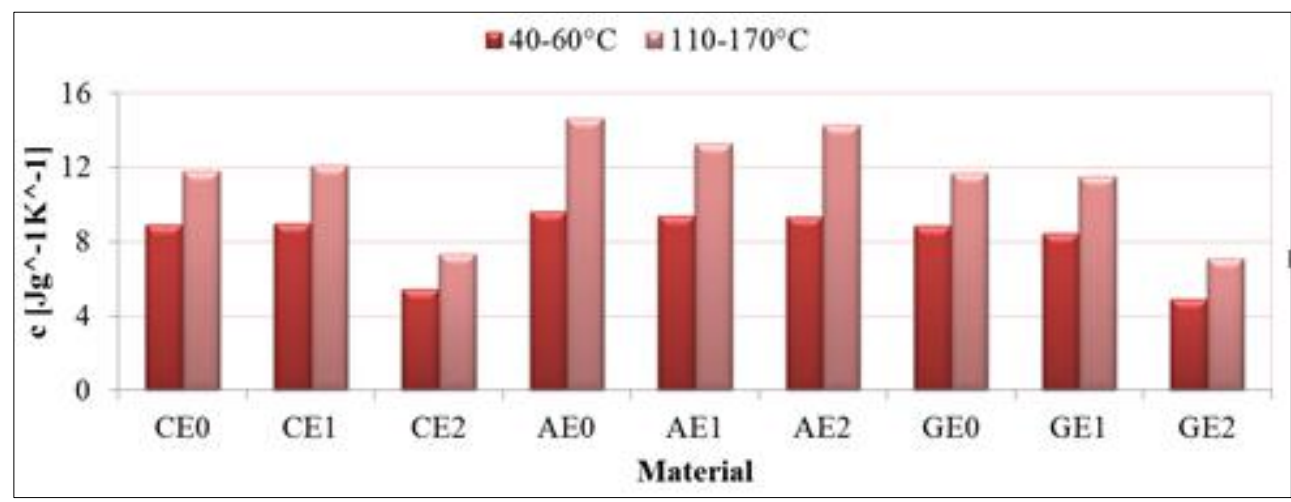

Figure 6. Specific heat of all fabric reinforced epoxy composite materials measured during heating on the targeted temperature domains

Regarding the influence of fiber orientation at various angles on specific heat of the composites (classes $\mathrm{C} 0$ and $\mathrm{C} 1$ ), it was obtained that only the values exhibited by composite reinforced with carbon fabric increased on both heating temperature ranges. In case of composites reinforced with aramid and glass fabric, the fiber orientation at various angles led to the decreasing of their specific heat values. If we compare the specific heat of composite materials of classes $\mathrm{C} 1$ and $\mathrm{C} 2$, it can be observed that the 
filler mixtures addition into epoxy matrix fabric reinforced epoxy composites with fiber orientation at various angles led to the decreasing of specific heat values of all composites in the temperature ranges of $40-60^{\circ} \mathrm{C}$ and $110-170^{\circ} \mathrm{C}$, except for the composite reinforced with aramid fabric, which showed an increase of specific heat in the temperature range of $110-170^{\circ} \mathrm{C}$. If we compare the materials of classes $\mathrm{C} 1$ and $\mathrm{C} 2$, it can be seen that the fiber orientation at various angles and filler addition into epoxy matrix insignificantly influenced the specific heat values of composite reinforced with aramid fabric on both heating temperature ranges.

In case of composite reinforced with carbon fabric, it was obtained that the values of specific heat were reduced by almost $38 \%$ on both temperature ranges of $40-60^{\circ} \mathrm{C}$ and $110-170^{\circ} \mathrm{C}$, if we compare materials of classes $\mathrm{C} 0$ and $\mathrm{C} 2$. The specific heat measured for composite reinforced with glass fabric showed a decreasing of values in the temperature ranges of $40-60^{\circ} \mathrm{C}$ and $110-170^{\circ} \mathrm{C}$ by almost $42 \%$ and $39 \%$ respectively.

The averaged values of specific heat of epoxy composites reinforced with fabrics, measured in the cooling temperature ranges of $40-60^{\circ} \mathrm{C}$ and $110-170^{\circ} \mathrm{C}$, are plotted in Figure 7. Generally, all investigated composite materials showed lower specific heat on both cooling temperature ranges as compared with those obtained in the heating temperature ranges, excepting composite reinforced with carbon fabric with fiber orientation at various angles and stratified filled epoxy matrix in the temperature range of $40-60^{\circ} \mathrm{C}$. If we compare the materials of class $\mathrm{C} 0$, it can be seen that the one reinforced with carbon fabric showed the highest value of specific heat in the temperature range of $40-60^{\circ} \mathrm{C}$ and the one reinforced with aramid fabric showed the highest value of specific heat in the temperature range of 110$170^{\circ} \mathrm{C}$.

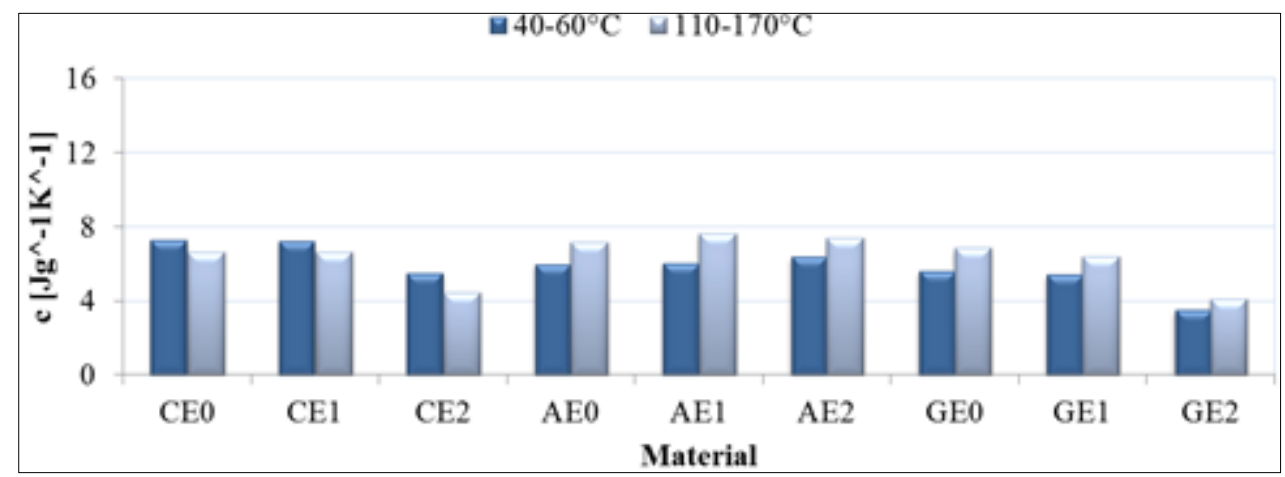

Figure 7. Specific heat of all fabric reinforced epoxy composite materials measured during cooling on the temperature targeted domains

If we compare the composite materials of classes $\mathrm{C} 0$ and $\mathrm{C} 1$, it can be observed that the fiber orientation at various angles influenced insignificantly the specific heat measured on the cooling curves. Filler mixtures addition into epoxy matrix led to a decreasing of their specific heat values of the composites with fiber orientation at various angles reinforced with carbon and glass fabrics. In case of composite material reinforced with aramid fabric, the fiber orientation at various angles and filler addition influenced insignificantly its specific heat. If we compare the specific heat investigated on both cooling temperature ranges of $40-60^{\circ} \mathrm{C}$ and $110-170^{\circ} \mathrm{C}$ of all materials, it can be seen that the ones reinforced with carbon fabric showed lower values in the temperature range of $110-170^{\circ} \mathrm{C}$ then those measured in the temperature range of $40-60^{\circ} \mathrm{C}$ as compared to the ones reinforced with aramid and glass fabrics, which exhibited higher values in the temperature range of $110-170^{\circ} \mathrm{C}$ then those measured in the temperature range of $40-60^{\circ} \mathrm{C}$.

\section{Conclusions}

The thermal coefficient of linear expansion and specific heat of three classes of epoxy composite materials reinforced with carbon, aramid, glass and hybrid fabrics and with unfilled and filled stratified 
matrix was analyzed. It was, also, investigated the fiber orientation $\left(0^{\circ}, \pm 15^{\circ}, \pm 30^{\circ}\right.$ and $\left.\pm 45^{\circ}\right)$ and two types of filler mixtures added into epoxy matrix of the composites. Based on the recorded experimental data presented in this work, there can be drawn the conclusions as follows:

The addition of the carbon black, barium ferrite and aramid powder into epoxy matrix decreased the values presented by thermal coefficient of linear expansion on both temperature ranges, leading to an improvement of its thermomechanical behavior. The epoxy matrix filled with aramid powder and carbon black (MM1) exhibited a reduction of thermal expansion coefficient in the temperature ranges of 40$60^{\circ} \mathrm{C}$ and $110-170^{\circ} \mathrm{C}$ by almost $50 \%$ and $25 \%$ respectively. The filled epoxy matrix filled with barium ferrite and carbon black (MM2) presented a decreasing of the this coefficient temperature ranges of 40$60^{\circ} \mathrm{C}$ and $110-170^{\circ} \mathrm{C}$ by almost $46 \%$ and $22 \%$ respectively. In case of specific heat measurements, it was found that the fillers had an insignificantly influence.

In case of materials with fiber orientation at $0^{\circ}$, the composite reinforced with carbon fabric presented the lowest thermal expansion coefficient in the temperature range of $40-60^{\circ} \mathrm{C}$ and the composite reinforced with aramid fabric exhibited the lowest values of this coefficient in the second temperature range of $110-170^{\circ} \mathrm{C}$.

In the heating temperature range of $40-60^{\circ} \mathrm{C}$ the fiber orientation at various angles improved the thermomechanical behavior of all fabric reinforced epoxy composites of class $\mathrm{C} 1$ materials. So, the expansion coefficient value was decreased by almost $33 \%$ in case of composite reinforced with carbon fabric. Regarding the specific heat of the composites it was recorded on both heating temperature ranges an increase for the ones reinforced with carbon fabric and a decrease for the ones reinforced with aramid and glass fabrics. The specific heat measured in the cooling temperature ranges showed an insignificantly influence of fiber orientation.

The addition of filler mixtures into epoxy matrix enhanced the thermomechanical behavior of composite materials reinforced with carbon and glass fabric and reduced the specific heat values of all epoxy composites on both temperature ranges, except composite reinforced with aramid fabric. The filler mixtures had insignificantly effects on specific heat of the composites reinforced with fabrics in the cooling temperature ranges.

Comparing the epoxy composites of classes $\mathrm{C} 0$ and $\mathrm{C} 2$ materials, the influence of fiber orientation at various angles and filler mixtures added into epoxy matrix reduced the values of linear expansion coefficient by almost $58 \%$ for composites reinforced with carbon and glass fabrics in the temperature range of $40-60^{\circ} \mathrm{C}$ and those of aramid reinforced epoxy composite increased by almost $5 \%$. In the temperature range of $110-170^{\circ} \mathrm{C}$ a decreasing by almost $24 \%$ of thermal coefficient value was found in case of glass reinforced epoxy composite. In case of specific heat measurements on both temperature ranges it was obtained a reduction of values by almost $38 \%$ for composite reinforced with carbon fabric and by almost $42 \%$ and $39 \%$ respectively for composite reinforced with glass fabric.

Acknowledgements. This work has been funded by the European Social Fund through the Sectoral Operational Programme Human Capital 2014-2020, through the Financial Agreement with the title „Burse pentru educaţia antreprenorială în rândul doctoranzilor şi cercetătorilor postdoctorat (Be Antreprenor!)" (in Romanian: "Scholarships for entrepreneurial education among doctoral students and postdoctoral researchers (Be Entrepreneur!)", Contract no. 51680/09.07.2019 - SMIS code: 124539. This work was also supported by the Project "EXPERT", Contract no. 14PFE/17.10.2018.

\section{References}

1.P. VIDAL, L. GALLIMARD, I. RANC, O. POLIT, Thermal and thermo-mechanical solution of laminated composite beam based on a variables separation for arbitrary volume heat source locations, Applied Mathematical Modelling. 46 (2017) 98-115. https://doi.org/10.1016/j.apm.2017.01.064.

2.A.R. GHASEMI, M. MORADI, Low thermal cycling effects on mechanical properties of laminated composite materials, Mechanics of Materials. 96 (2016) 126-137. https://doi.org/10.1016/j.mechmat. 2016.01.012. 
3.S.A. GRAMMATIKOS, R.G. JONES, M. EVERNDEN, J.R. CORREIA, Thermal cycling effects on the durability of a pultruded GFRP material for off-shore civil engineering structures, Composite Structures. 153 (2016) 297-310. https://doi.org/10.1016/j.compstruct.2016.05.085.

4.R. JOVEN, R. DAS, A. AHMED, P. ROOZBEHJAVAN, B. MINAIE, Thermal properties of carbon fiber-epoxy composites with different fabric weaves, International SAMPE Technical Conference. (2012).

5.M. REYNE, Technologie des composites, Hermès, Paris, 1995.

6.A. CAPATINA, V. BRIA, M. BUNEA, I.G. BIRSAN, Tensile Behaviour of Fabric Reinforced Laminates and Plies, Mater. Plast., 56(2), 2019, 370-377.

7.A.A. BAKER, S. DUTTON, D. KELLY, eds., Composite materials for aircraft structures, 2nd ed, American Institute of Aeronautics and Astronautics, Reston, VA, 2004.

8.K. DONG, K. LIU, Q. ZHANG, B. GU, B. SUN, Experimental and numerical analyses on the thermal conductive behaviors of carbon fiber/epoxy plain woven composites, International Journal of Heat and Mass Transfer. 102 (2016) 501-517. https://doi.org/10.1016/j.ijheatmasstransfer.2016.06.035.

9.G. KALOGIANNAKIS, D. VAN HEMELRIJCK, G. VAN ASSCHE, Measurements of Thermal Properties of Carbon/Epoxy and Glass/Epoxy using Modulated Temperature Differential Scanning Calorimetry, Journal of Composite Materials. 38 (2004) 163-175. https://doi.org/10.1177/ 0021998304038647.

10.R. JOHN, G. ATXAGA, H.J. FRERKER, A. NEWERLA, Advancement of Multifunctional support structure technologies (AMFSST), in: 2007 13th International Workshop on Thermal Investigation of ICs and Systems (THERMINIC), IEEE, Budapest, Hungary, 2007: pp. 98-103. https://doi.org/ 10.1109/THERMINIC.2007.4451755.

11.H. YU, A. NONN, S. SCHNEIDERS, D. HEIDER, S.G. ADVANI, An approach to enhance throughthickness thermal conductivity of polymeric fiber composites, International Journal of Heat and Mass Transfer. 59 (2013) 20-28. https://doi.org/10.1016/j.ijheatmasstransfer.2012.11.055.

12.W. BIAN, T. YAO, M. CHEN, C. ZHANG, T. SHAO, Y. YANG, The synergistic effects of the micro-BN and nano-Al2O3 in micro-nano composites on enhancing the thermal conductivity for insulating epoxy resin, Composites Science and Technology. 168 (2018) 420-428. https://doi.org/ 10.1016/j.compscitech.2018.10.002.

13.R.S. PRAVEEN, S. JACOB, C.R.L. MURTHY, P. BALACHANDRAN, Y.V.K.S. RAO, Hybridization of carbon-glass epoxy composites: An approach to achieve low coefficient of thermal expansion at cryogenic temperatures, Cryogenics. 51 (2011) 95-104. https://doi.org/10.1016/j. cryogenics.2010.12.003.

14.A. SAHU, D.S. MONDLOE, S.C. UPADHYAY, A review on thermal properties of epoxy composites as thermal interface material, International Research Journal of Engineering and Technology (IRJET). 04 (2017) 579-586.

15.E. KANDARE, A.A. KHATIBI, S. YOO, R. WANG, J. MA, P. OLIVIER, N. GLEIZES, C.H. WANG, Improving the through-thickness thermal and electrical conductivity of carbon fibre/epoxy laminates by exploiting synergy between graphene and silver nano-inclusions, Composites Part A: Applied Science and Manufacturing. 69 (2015) 72-82. https://doi.org/10.1016/j.compositesa. 2014.10.024.

16.V.V. VASILIEV, E.V. MOROZOV, Mechanics and analysis of composite materials, 1st ed, Elsevier Science, New York, 2001.

17.M. XANTHOS, ed., Functional fillers for plastics, 2., updated and enlarged ed, Wiley-VCH, Weinheim, 2010.

18.M. RAFIEE, F. NITZSCHE, J. LALIBERTE, S. HIND, F. ROBITAILLE, M.R. LABROSSE, Thermal properties of doubly reinforced fiberglass/epoxy composites with graphene nanoplatelets, graphene oxide and reduced-graphene oxide, Composites Part B: Engineering. 164 (2019) 1-9. https://doi.org/10.1016/j.compositesb.2018.11.051. 
19.J. CHEN, X. GAO, W. SONG, Effect of various carbon nanofillers and different filler aspect ratios on the thermal conductivity of epoxy matrix nanocomposites, Results in Physics. 15 (2019) 102771. https://doi.org/10.1016/j.rinp.2019.102771.

20.S. HAN, Q. MENG, Z. QIU, A. OSMAN, R. CAI, Y. YU, T. LIU, S. ARABY, Mechanical, toughness and thermal properties of 2D material- reinforced epoxy composites, Polymer. 184 (2019) 121884. https://doi.org/10.1016/j.polymer.2019.121884.

21.N. ABDEL-AAL, F. EL-TANTAWY, A. AL-HAJRY, M. BOUOUDINA, Epoxy resin/plasticized carbon black composites. Part I. Electrical and thermal properties and their applications, Polymer Composites. 29 (2008) 511-517. https://doi.org/10.1002/pc.20401.

22.T. BERA, S.K. ACHARYA, P. MISHRA, Synthesis, mechanical and thermal properties of carbon black/epoxy composites, International Journal of Engineering, Science and Technology. 10 (2018) 1220. https://doi.org/10.4314/ijest.v10i4.2.

23.I.G. BIRSAN, V. BRIA, A. CIRCIUMARU, I. ROMAN, Characterisation of particulate epoxy composites, The Annals of University "Dunărea de Jos" of Galati, Fascicle VIII. XV (2009) 83-87.

24.M. BUNEA, R. BOSOANCA, A. COJAN, I.G. BIRSAN, Thermomechanical and Electrical Properties of Fabric Reinforced Laminates with Filled Stratified Epoxy Matrix, Mater. Plast., 55(3), 2018 269-273.

25.V. STEFANESCU, A. BOBOC, A. COJAN, R. BOSOANCA, C. MUNTENITA, M. BUNEA, The Thermal Behavior of Hybrid Fabric Reinforced Composites with Stratified Filled Epoxy Matrix, Mater. Plast., 55(2), 2018, 161-166.

26.V. BRIA, A. CIRCIUMARU, I.G. BIRSAN, Some Properties of Starch/Epoxy Composites, Mater. Plast., 48, 2011, 189-194.

$\overline{\text { Manuscript received: } 13.05 .2020}$ 